\title{
SOBRE EL ORIGEN DEL SESEO CARTAGENERO
}

\author{
ALFONSO GRANDAL LÓPEZ
}

\section{Introducción: la tesis del origen andaluz y las dificultades que plantea}

La opinión más difundida sobre el seseo cartagenero, propugna para éste un origen andaluz, basándose, por una parte en la articulación de la $s$ cartagenera, presuntamente predorsal y, por otra, en unas hipotéticas migraciones de mineros y pescadores andaluces hacia Cartagena, que justificarían la presencia en esta ciudad y su territorio de dicho fenómeno lingüístico ${ }^{1}$.

Ahora bien, para poder admitir este origen andaluz del seseo cartagenero, es necesario haber comprobado que, efectivamente, se dan algunas condiciones previas imprescindibles, como son:

$1^{\circ}$ Que en Cartagena es o ha sido mayoritaria la $s$ predorsal «andaluza».

$2^{\circ}$ Que el seseo cartagenero es claramente posterior al andaluz (y no solo al sevillano).

$3^{\circ}$ Que, en la época de surgimiento del seseo cartagenero, se registra una fuerte inmigración de andaluces en la ciudad o una relación particularmente estrecha con zonas seseantes de Andalucía.

$4^{\circ}$ Que no hay otras hipótesis que expliquen satisfactoriamente el fenómeno.

En cuanto al primer punto, solo diremos que convendría estudiarse con mayor profundidad el asunto de la articulación de la $s$ cartagenera, antes de que ésta pierda definitivamente sus rasgos característicos, con el fin de comprobar hasta qué punto el seseo cartagenero está más cerca del almeriense que del de la Vega Baja, por ejemplo.

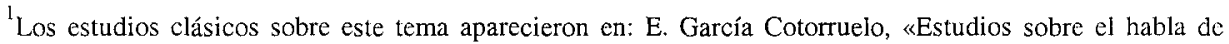
Cartagena y su comarca», Anejos del Boletín de la Real Academia Española, Madrid, 1959 y G. García Martínez, El habla de Cartagena: palabras y cosas, Murcia, 1960, reimpág. por la Universidad de Murcia en 1986. Recientemente, J. Muñoz Garrigós ha ofrecido un completo resumen de estas ideas en la Gran Enciclopedia de la Región de Murcia, Murcia, 1993, vol. 3, pág. 99.
} 
Nos centraremos, pues, en las otras tres cuestiones. Sobre la antigüedad del seseo cartagenero, podemos demostrar documentalmente que se encontraba generalizado, como muy tarde, en los años treinta del siglo XVI, pues, por aquellas fechas, algunos escribanos de la ciudad eran ya incapaces de distinguir correctamente $s / s s$ y $z / c^{2}$. Veamos algunos ejemplos, procedentes de las catas efectuadas en la documentación del Archivo Municipal de Cartagena.

En uno de los poquísimos documentos de principios del siglo XVI que han llegado hasta nosotros, el padrón de vecinos que se hizo en 1505, con el fin de recaudar dinero para la conquista de Mazalquivir ${ }^{3}$, encontramos algunos indicios de seseo, pero, al tratarse casi siempre de la sustitución de $z$ por $s$, no podemos considerarlos como pruebas definitivas, ya que por entonces el signo $\sigma$ aun se usaba para transcribir tanto $s$ como $z$. Aunque no siempre tenemos $\sigma$ : a final de palabra alterna ésta con $s$ alta en sustitución de $z$.

Así vemos escrito muchas veces dosientos y, de vez en cuando $\left(\mathrm{f}^{\circ} 16 \mathrm{r}^{\circ}, 18 \mathrm{r}^{\circ}, 18 \mathrm{v}^{\circ}\right)$, dozientos. Lo mismo ocurre con tresientos y trezientos $\left(\mathrm{f}^{\mathrm{o}} 2^{\circ} \mathrm{v}^{\circ}\right)$. Sin embargo, siempre tenemos quatroçientos, seysçientos o seteçientos. En el libro de cuentas del Concejo de los años 1505-1506 ${ }^{4}$, también alternan tresientos $\left(\mathrm{f}^{\circ} 14 \mathrm{r}^{\circ}\right)$ y trezientos $\left(\mathrm{f}^{\circ} 10 \mathrm{r}^{\circ}\right)$, dies e seys $\left(\mathrm{f}^{\mathrm{D}} 13 \mathrm{r}^{\circ}\right)$, dies e nueve $\left(\mathrm{f}^{\mathrm{D}} 14 \mathrm{v}^{\circ}\right)$ y diez e ocho $\left(\mathrm{f}^{\mathrm{D}} 10 \mathrm{v}^{\circ}\right)$. La forma dosientos vuelve a aparecer en otro escrito de $1512^{5}$.

En cuanto a los nombres propios, en el padrón de 1505 pueden leerse los siguientes: Albarrasin $\left(\mathrm{f}^{\mathrm{o}} 2 \mathrm{v}^{\circ}\right)$, Ezpin (una vez $-\mathrm{f}^{\mathrm{o}} 2 \mathrm{r}^{\circ}$-, pero normalmente, Espin), Lasaro $\left(\mathrm{f}^{\circ} 19 \mathrm{r}^{\circ}\right.$, $\left.25 \mathrm{r}^{\circ}\right)$, Ruis $\left(\mathrm{f}^{\mathrm{o}} 8 \mathrm{r}^{\circ}\right)\left(\right.$ y Royz, $\left.\mathrm{f}^{\circ} 10 \mathrm{r}^{\circ}\right)$, Sanches $\left(\mathrm{f}^{\mathrm{o}} 8 \mathrm{r}^{\circ}\right)$, Ferrandes $\left(\mathrm{f}^{\mathrm{o}} 8 \mathrm{r}^{\circ}\right)$, Yvañes $\left(\mathrm{f}^{\mathrm{o}} 9 \mathrm{r}^{\circ}\right)$, Martines $\left(\mathrm{f}^{\circ} 9 \mathrm{r}^{\circ}\right)$, Mendes $\left(\mathrm{f}^{\circ} 16 \mathrm{r}^{\circ}\right)$, pero Lopez $\left(\mathrm{f}^{\mathrm{o}} 8 \mathrm{r}^{\circ}\right)$, Minguez $\left(\mathrm{f}^{\circ} 9 \mathrm{r}^{\circ}\right)$, Ortiz $\left(\mathrm{f}^{\circ} 9 \mathrm{r}^{\circ}\right)$, Perez $\left(\mathrm{f}^{\circ} 11 \mathrm{v}^{\circ}\right)$, Diaz $\left(\mathrm{f}^{\circ} 10 \mathrm{r}^{\circ}\right)$, Rodriguez $\left(\mathrm{f}^{\circ} 16 \mathrm{v}^{\circ}\right)$. Los apellidos catalanes se prestan poco a este tipo de vacilaciones, pero podemos señalar Borraz $\left(f^{0} 10 r^{\circ}\right)$. Aparecen

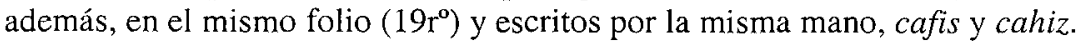

En el citado libro de cuentas, tenemos alguasil $\left(\mathrm{f}^{\mathrm{0}} 16 \mathrm{r}^{\circ}\right)$ y Juan Dias $\left(\mathrm{f}^{\circ} 13 \mathrm{v}^{\circ}\right)$, mientras que en otro documento de $1520^{6}$ leemos Peres.

\footnotetext{
${ }^{2}$ Hasta hace poco era opinión casi unánime que hacia 1500 todavía se pronunciaba, en las zonas más conservadoras de Castilla, como Toledo y su área de influencia, - $s-$ como $[z]$, ss como [s], las dos apicales, $z$ como $[t z] 0[z]$ y $s$ como [ts]o[s], éstas predorsales. A lo largo de la primera mitad del siglo XVI $\mathrm{y}$, a partir de Castilla la Vieja, se extendió rápidamente un modelo simplificado que solo distinguía entre una $s$ apical $<[s]$ y $[z]$ y otra $s$ predorsal $<[t s]$ y $[t z]$, que, más adelante, acabó haciéndose interdental $[\theta]$. Hoy, autores como Frago Gracia adelantan la fecha de estos cambios y cuestionan su origen norteño (J. A. Frago Gracia, Historia de las hablas andaluzas, Madrid, 1993)

${ }^{3}$ Caja 79, Expediente 28. Así consta en la ficha catalográfica del Archivo, pero podría ser unos años anterior.

${ }^{4}$ C. 79, E. 31

${ }^{5}$ C. 79 , E. $35, f^{\circ} 3 v^{\circ}$

${ }^{6}$ C. 79 , E. $34, f^{\circ} 3 r^{\circ}$
} 
Vemos, pues, que solo Ezpín y Borraz podemos aceptarlos como posibles pruebas de confusión entre $[s] /[z]$ apicales y $[s] /[z]$ predorsales, mientras que las demás alternancias, pueden ser simples vacilaciones ortográficas.

Los primeros casos claros de confusión se han localizado en unos años en los que la documentación conservada empieza a ser un poco más abundante. En el libro de Actas de 1537-1542, ya en el folio $2 \mathrm{v}^{\circ}$ (3-7-1537), aparece haser y pezos, y, más adelante ( $\mathrm{f}^{\mathrm{o}}$ $\left.12 v^{\circ}, 13-8-1537\right)$, dehezas y, de nuevo, pezas y pezos $\left(16-8-1537, \mathrm{f}^{\circ} 13 \mathrm{r}^{\circ}\right)$, Retamoza y Retamosa $\left(64 \mathrm{r}^{\circ}\right)$, Ruiz y Rois (con s y no con $\sigma$ ), etc. Saltamos a 1559 y, en el libro de Cuentas de Propios de 1558-59, encontramos surujano (por çurujano o cirujano), mientras que, en las Actas Capitulares de 1558-59 (26-2-1559), tenemos çaçerdote. Del año siguiente, 1560, es un documento sobre la ordenanza del Pósito ${ }^{7}$, en el que las faltas de ortografía proliferan: dies e nueve, proviçion, poçito (por pósito), senço (por censo), senso, nesesarias, nessesarias, defença, haser, disen, veses, conçervar, nessesidad, depoçito, etc. En las Actas Capitulares de 1560-61, tenemos, por ejemplo, sarsos, aserca dello, rrazo (junto a rraso) (22-2-1561, $\left.\mathrm{f}^{\mathrm{o}} 37 \mathrm{v}^{\circ}\right)$; calsada, crus (1-3$\left.1561, \mathrm{f}^{\circ} 39 \mathrm{r}^{\circ}\right)$.

A partir de mediados de siglo, estos casos de confusión se multiplican y pueden aparecer en cualquier documento, incluso en las copias de cartas reales, como los çufiçientes, çufiçiençia, acresentamos, etc, de la carta real trascrita en 10 s $\mathrm{f}^{\circ} \mathrm{s} 96 \mathrm{r}^{\circ}-97 \mathrm{v}^{\circ}$ de las A.C. de 1561-62. De los años setenta tenemos un texto del 14-10-1572 en el que se pide permiso «para haser çiertas sanjas y creser el agua» ${ }^{8}$, y así se podrían seguir aportando infinitos ejemplos, sobre todo en aquellos documentos que, como las peticiones al Concejo por parte de los vecinos, reflejan a veces con más claridad la pronunciación popular, y que se han conservado a partir de estos años: Mansanares, bezamos, nozotros, aderesadas, servisio, plasas, nesesario, lisençia?.

Naturalmente, el seseo andaluz es algo anterior a las fechas en las que aparecen los primeros indicios de Cartagena ${ }^{10}$, por lo menos en Sevilla, pero la documentación

\footnotetext{
${ }^{7}$ C. 112, E. 29

${ }^{8}$ A.C. $1572-1574$

${ }^{9}$ C. 90 , E. 5
}

${ }^{10}$ A finales del siglo XV en Sevilla y su zona de influencia ya solo se distinguía entre una $s$ predorsal sorda y otra, también predorsal, pero sonora, habiéndose perdido las apicales. En la segunda mitad del siglo XVI, triunfa en Andalucía la tendencia castellana a ensordecer las sibilantes y se pierde la $s$ sonora, quedando una sola $s$ sorda. A. Zamora Vicente, Dialectología española, Madrid, 1974, págs. 303-307; R. Lapesa, Historia de la lengua española, Madrid, 1968, pág. 191; F. Abad Nebot, «Seseo y ceceo como problema de linguística general», Introducción plural a la granática histórica, Madrid, 1983, págs. 88-95; D. Catalán, «El fin del fonema /z/ [dz-z] en español», Introducción ..., págs. 96-129. Frago Gracia, por su parte, presenta casos de confusión entre $s$ y $\varsigma$ desde finales del siglo XIII (Opág. cit. pág. 328) y demuestra que el fenómeno estaba ya generalizado en el siglo XV. Además mantiene este autor (y en la documentación de Cartagena se aprecia también esta circunstancia) que la distinción entre $[s]$ ( $s$ sorda) y $[z]$ ( $s$ sonora) ya estaba en decadencia o había desaparecido por entonces. 
cartagenera de la Edad Media y de los primeros decenios del siglo XVI es muy escasa y pobre en comparación con la del resto de esta centuria, por lo que podrían haberse perdido, con la documentación desaparecida, testimonios de seseo más tempranos y menos dudosos que los mencionados más arriba ${ }^{11}$. Además, como señala Frago Gracia, entre los últimos decenios del siglo XV y los primeros del XVI, tiene lugar en la documentación andaluza una irrupción bastante brusca de grafías incorrectas, «que pasan en poco tiempo de ser relativamente dispersas a abundar extraordinariamente ${ }^{12}$, lo que achaca este autor al relajamiento de las normas ortográficas, cada vez más alejadas de la pronunciación normal. Y en Cartagena también puede observarse este fenómeno, aunque con un poco de retraso respecto a la documentación andaluza: aquí la descomposición ortográfica se difunde en los primeros decenios del siglo XVI. Podemos concluir, pues, que la confusión de $[s] /[z]$ apicales y $[s] /[z]$ predorsales puede haberse iniciado en Cartagena, como muy tarde, por los mismos años que en Andalucía, con la probable excepción de Sevilla.

En cuanto al asentamiento de una cantidad considerable de andaluces en Cartagena durante el siglo XVI o una intensificación de las relaciones con los puertos andaluces y con Granada, que pudieran justificar un cambio fonético de estas características, podemos afirmar lo siguiente:

Por una parte, sabemos que, durante los últimos años del siglo XV y todo el XVI, que es la época que aquí interesa, Andalucía es una región de fuerte inmigración (definitiva o de paso para América) y poca emigración (salvo hacia el Nuevo Continente). Por otra parte, y gracias a los trabajos de R. Torres ${ }^{13}$, conocemos con bastante precisión el origen de los inmigrantes que se asentaron en Cartagena a partir de 1567 , y nada hace suponer que los llegados durante la primera mitad del siglo tuvieran una procedencia muy distinta.

Según este autor, de 1567 a 1639 , entre el $30 \%$ y el $50 \%$ de los forasteros avecindados o casados en Cartagena cuyo origen se conoce ${ }^{14}$, eran extranjeros (según el concepto actual de extranjero $=$ no español y no según el de entonces $=$ no

\footnotetext{
${ }^{11}$ La obra de Isabel García Díaz, La escritura en Cartagena en el siglo XV, Cartagena, 1999, aparecida cuando ya estaba este trabajo en la imprenta, ha venido a confirmar nuestra suposición. En las cartas enviadas por el Ayuntamiento de Cartagena a los de Murcia y Orihuela (conservadas en los archivos municipales de estas ciudades), aparecen algunos testimonios de seseo como nesesaria, en una carta de 1431 (pág. 91); lişa y (caso dudoso) muçola (dos nombres de pescados de origen catalán), de 1477 (pág. 115) o sienpre y poçebilidad, de 1488 (págs. 130-131).

12 Opág. cit. pág. 355 .

${ }^{13}$ Los datos de población del presente trabajo están tomados de R. Torres Sánchez, Ciudad y población: el desarrollo demográfico de Cartagena durante la Edad Moderna, Cartagena, 1998. También puede verse, del mismo autor, «Evolución de la población de Cartagena durante la época de los Austrias (siglos XVI-XVII)», Historia de Cartagena, Murcia, 1994, vol. VII, págs. 29-94

${ }^{14}$ Los casos estudiados por $\mathrm{R}$. Torres son más de mil, lo que permite hacerse una idea bastante clara, aunque desde luego no rigurosamente exacta, de la procedencia de estos forasteros
} 
castellano). El $20 \%$ aproximadamente, procedía de la propia región de Murcia y sobre un $40 \%$ del resto de España. Este 40\% agrupaba, entre otros, entre un $15 \%$ y un $20 \%$ de castellanos de las dos Castillas (con amplio predominio manchego), un 10\%, como máximo, de valencianos, mallorquines y catalanes, y menos de un $8 \%$ de andaluces.

Por lo que se refiere a la población flotante de Cartagena en aquellos tiempos, estaba formada por una mezcla de marineros, comerciantes y trajineros de la región de Murcia, de Castilla y de todos los puertos del Mediterráneo y no pocos del Atlántico, por pastores y segadores manchegos, soldados castellanos (en sentido amplio, o sea, de toda la Corona de Castilla) y extranjeros de paso por la ciudad hacia sus destinos, galeotes de toda España, moriscos, pescadores de la zona de Alicante, esclavos berberiscos, etc. Es decir, nada apunta hacia una presencia especialmente abundante de andaluces entre los transeuntes que frecuentaban la ciudad.

En cuanto a las relaciones con Andalucía, no cabe duda que aumentaron intensamente a lo largo del siglo XVI, en particular con Sevilla, pero en la misma o mayor proporción aumentaron con otros grandes puertos españoles y extranjeros, y lo mismo podría decirse respecto a Granada, ciertamente más visitada ahora con motivo de los pleitos que se juzgan en la Chancillería y de las relaciones comerciales, pero menos que Madrid, por ejemplo.

Es evidente, pues, que ni la intensidad de las relaciones con Andalucía, ni el número de inmigrantes o transeuntes andaluces presentes en la ciudad durante el quinientos, justifican los cambios en los hábitos de pronunciación del conjunto de la población cartagenera que se dieron por entonces.

\section{Posibles alternativas}

Si hemos visto que la tesis andaluza no puede satisfacer, veamos ahora qué alternativas se nos ofrecen. En primer lugar, y en vista de que no podemos tener la seguridad de que la $s$ cartagenera fuese predorsal en el siglo XVI, se podría aventurar Ia hipótesis de que el seseo fuera motivado, como ocurrió en Orihuela ${ }^{15}$, por un influjo catalán ${ }^{16}$. En otros trabajos he apuntado la posibilidad de que, al menos una parte de la población de Cartagena, mantuviera la lengua catalana hasta los primeros decenios del

\footnotetext{
${ }^{15}$ M. Abad Merino, El cambio de lengua en Orihuela. Estudio sociolingüístico-histórico del siglo XVII, Murcia, 1994

${ }^{16}$ E $\rfloor$ seseo catalán, con s apical, se había generalizado hacia 1400: E. Alarcos Llorach, Estudis de linguiística catalana, Barcelona, 1983, pág. 109. Pilar Díez de Revenga muestra ejemplos de trueque de $s$ y $s$ en documentos murcianos del siglo XIII redactados en castellano por un escribano catalán («Estudio lingüístico de documentos murcianos del siglo XIII (1243-1283)», Miscelánea Medieval Murciana, vol. Il (1976), Murcia, págs. 15-16)
} 
siglo $\mathrm{XVI}^{17}$, con lo que no tendría nada de particular que un número considerable de cartageneros seseara (¿con $s$ apical?) y que, reforzados por el amplio porcentaje de inmigrantes que tendrían dificultades para distinguir $s$ de $\varsigma$ al modo castellano, acabaran por contagiar a toda la población este hábito. A este respecto, es significativo que el cartagenero Gaspar Dávila ${ }^{18}$ achaque a influencia valenciana este «vicio» de sus paisanos, aun después de advertir que es «costumbre de los sevillanos».

Pero ni siquiera es necesario este posible sustrato catalán para explicar la aparición del seseo en Cartagena. Si nos fijamos en la evolución de la población a lo largo del siglo XVI y recordamos el origen de los inmigrantes, se hace evidente que la neutralización de la distinción entre $[s]$ apical y $[s]$ predorsal era casi inevitable.

En efecto, a principios de siglo vivían en Cartagena unas 1.500 personas y hacia 1550 se habían alcanzado los 5.000 habitantes, la mayoría de ellos forasteros o hijos de forasteros. Pues bien, si sumamos los extranjeros, los catalanoparlantes y los andaluces que se establecieron en la ciudad, tenemos más de un $60 \%$ del total de los forasteros, lo que supone un contingente más que suficiente para imponer la tendencia a sesear que compartían casi todos. También la composición de este grupo de inmigrantes (muchos más norteafricanos, italianos, franceses, portugueses y andaluces que catalanoparlantes), explica el posible predominio final de las variantes predorsales sobre la apical en la pronunciación de la $s$.

Mirando el asunto desde otro punto de vista, se ve, además, que no hay un solo lugar en toda la costa entre Nápoles y Vigo donde se distinga $s$ de $z$ a la manera de Castilla $^{19}$. Por casi todas partes, o solo se conoce una $s$ (apical en valenciano apitxat, predorsal en andaluz), o se distingue entre una $s$ sonora y otra sorda (apicales en el resto del territorio de lengua catalana y una pequeña parte de la costa portuguesa o predorsales en casi todo Portugal, Occitania y Norte de Italia ${ }^{20}$ ). En cuanto al Centro y Sur de Italia, que distingue $s$ de $z$, lo hace de forma tan diferente a la castellana, que los nativos de allí, al hablar nuestro idioma acaban seseando también. Como esta distribución, a falta de pequeños retoques, estaba ya establecida en el siglo XVI, era muy difícil que en Cartagena se hubiera podido mantener la distinción, cuando buena

${ }^{17}$ A. Grandal López, «Historia lingüística de Cartagena durante la Edad Media», Historia de Cartagena, Murcia, 1986, vol.VI, págs. 407-420; «Algunes dades sobre la toponímia cartagenera d'origen cátala», Butlletí Interior de la Societat d'Onomàstica, vol. XXV (1986), pág. 5, y «Algunes empremtes de la permanència del català a la comarca de Cartagena (Múrcia): del segle XIII al XVI», Quaderns de Migjorn, n 3 (1996-1997), Alicante, págs. 103-116)

${ }^{18} \mathrm{G}$. Dávila, Compendio de la Ortografía Castellana, Madrid, 1631, cit. por A. Colao, Cartagena en los siglos XVI y XVII, Murcia, 1982, pág. 257

${ }^{19}$ Las excepciones de Aguilas y el Puerto de Mazarrón, sobre la que en seguida volveremos, son muy recientes, ya que esta parte de la costa estuvo desierta hasta el siglo XVIII

${ }^{20}$ En la región de Liguria, con la que tanta relación mantuvo Cartagena durante siglos, se da, precisamente, un caso parecido: mientras distingue el interior, sesea Génova y toda su costa (G. Rohlfs, Grammatica storica della lingua italiana e dei suoi dialetti: fonetica, Turin, 1970, pp .201-202) 
parte de la gente que llegaba a la ciudad procedía de los puertos de esta zona y las relaciones de la ciudad con ellos eran continuas y estrechas.

\section{La extensión del seseo}

La población cartagenera se concentraba en la ciudad hasta mediados del siglo XVI, y no inició la colonización del campo hasta la segunda mitad de este siglo. En 1561, con algo más de 5.000 habitantes (distintas dificultades, entre las que destaca la peste de 1558-59 habían obstaculizado el desarrollo de la población), sólo 156 vecinos y sus familias (en total unas 700 personas $^{21}$ ) tenían casa en el campo, y no todos las habitaban permanentemente. A principios del siglo XVII, ya vivía en el campo un tercio de la población y hacia 1640 la población rural probablemente superaba a la urbana 0 , por lo menos, la igualaba en número.

Ahora bien, esta población que se establece en el campo, lo hace, normalmente, tras haberse asentado previamente en la ciudad y cuando ha recibido tierras del Concejo, que administraba las grandes extensiones desiertas del término concejil.

Los datos expuestos nos ayudan a entender la curiosa extensión del seseo cartagenero, uniformemente distribuido por todo el término municipal, pero que raramente lo sobrepasa (naturalmente nos referimos al término municipal cartagenero tal como era en el siglo XVI, algo mayor que ahora). Ni siquiera la costa de Mazarrón sesea, siendo así que sí lo hace el interior ${ }^{22}$. La explicación es bien fácil: cuando los cartageneros repoblaron sus campos desiertos, ya seseaban, por lo que llevaron esta particularidad a todos los rincones de su término, pero llegaron hasta donde alcanzaba la jurisdicción de la ciudad. Más allá de la rambla del Albujón, fueron los vecinos de Murcia, apoyados por su concejo y ayudados por los de otros municipios limítrofes, quienes se encargaron de la repoblación del resto de la comarca.

\section{Algunas palabras sobre la decadencia del seseo}

En los siglos XVII y XVIII, las pruebas de seseo siguen proliferando sobre toda clase de documentos generados en Cartagena, pero a lo largo del siglo XIX

\footnotetext{
${ }^{21}$ Esta cifra no incluye el pequeño poblado minero de Alumbres, con unos 200 habitantes por aquel entonces, ni la parte de Fuente Alamo incluida en el término municipal de Cartagena, que no llegaba a los cien. En total, pues, la población rural podía representar $1 / 5$ del total como máximo

${ }^{22}$ El seseo mazarronero podría ser, si se remonta al siglo $\mathrm{XVI}$, una derivación del núcleo cartagenero, suponiendo que la mayoría de los pobladores de esta villa hubieran Ilegado de Cartagena, cosa poco probable. Por otra parte, la ausencia de seseo en el Puerto de Mazarrón, complica aun más el problema. Una de dos, o el Puerto se pobló con gente de fuera de Mazarrón (y de Cartagena ¿de Águilas?) o el seseo mazarronero es tan reciente que no existía aun en el siglo XVIII, cuando surge esta población costera, lo que también es más que dudoso. Esperemos que posteriores investigaciones puedan aclarar el misterio
} 
disminuirán rápidamente ante la presión creciente de la escuela. A comienzos del siglo actual puede situarse el inicio de la decadencia de este rasgo fonético, precisamente cuando alcanza, tras medio siglo de auge de la minería, su apogeo la inmigración andaluza. Si la escuela había conseguido durante el siglo anterior que las personas ilustradas distinguieran la $\mathrm{s}$ de la $\mathrm{z}$, por lo menos en la escritura, ahora irá imponiendo esta distinción en la pronunciación, con la cada vez más importante ayuda de los medios de comunicación. La Guerra Civil y sus traumáticas consecuencias, aceleraron el proceso de marginación del seseo y si antes de la guerra era ya considerado como un rasgo eminentemente popular, tras ella será tenido por vulgar y evitado en la medida de lo posible.

Aun quedan algunos testigos del inicio de este proceso de decadencia y muchos más de su desarrollo, por lo que urge un estudio sistemático que pueda fijar con certeza unas causas y etapas que aquí no podemos más que esbozar.

\section{Conclusión}

En resumen, de todo lo dicho se deduce que el seseo cartagenero difícilmente puede ser achacado a influencia andaluza. Ni su temprana fecha de aparición, ni la escasez de inmigrantes andaluces en Cartagena hasta por lo menos el siglo XVIII (y aun entonces seguirán siendo una minoría), nos permiten aceptar esta tesis. En cambio, podría pensarse en una consecuencia del contacto con el catalán, bien como lengua aun viva, bien como sustrato fuertemente activo. También es plausible la idea de que la neutralización de la distinción de $s$ y $c$, fuera debida a la presión ejercida por el aluvión de inmigrantes de distintas procedencias que sufrió la ciudad durante los años críticos de la primera mitad del siglo XVI. Y, desde luego, cabe considerar como muy probable una combinación de estas dos explicaciones: el incipiente seseo de la población cartagenera originaria, pudo ser reforzado y, quizá, modificado por una mayoría de forasteros que compartían la misma tendencia al seseo, aunque con otros matices.

En cuanto a la naturaleza del fenómeno, nada podemos concluir sobre la primitiva articulación de la $s$ cartagenera y bien poco sobre como se inició el proceso de seseo. Únicamente parece deducirse de los datos expuestos que la confusión pudiera haber afectado primero a la posición implosiva. Pero, a falta de más y mejores elementos de juicio, debemos considerar esta idea como una pura conjetura.

\section{Referencias bibliográficas:}

Abad Merino, M. (1994): El cambio de lengua en Orihuela. Estudio sociolinguíísticohistórico del siglo XVII, Murcia. 
Abad Nebot, F. (1983): «Seseo y ceceo como problema de linguística general», Introducción plural a la gramática histórica, Madrid.

Alarcos Llorach, E. (1983): Estudis de lingüística catalana, Barcelona.

Catalán, D. (1983): «El fin del fonema /z/ [dz-z] en español», Introducción plural a la gramática histórica, Madrid.

Colao, A. (1982): Cartagena en los siglos XVI y XVII, Murcia.

Dávila, G. (1631): Compendio de la ortografía castellana, Madrid.

Díez de Revenga Torres, P. (1986): «Estudio lingüístico de documentos murcianos del siglo XIII (1243-1283)», Miscelánea Medieval Murciana, vol. II (1976), Murcia, págs. 9-34.

Frago García, J. A. (1993): Historia de las hablas andaluzas, Madrid.

García Cotorruelo, E. (1959): «Estudios sobre el habla de Cartagena y su comarca», Anejos del Boletín de la Real Academia Española, Madrid.

García Díaz, I. (1999): La escritura en Cartagena en el siglo XV, Cartagen.

García Martínez, G. (1960): El habla de Cartagena: Palabras y cosas, Murcia.

Grandal López, A. (1986): «Historia lingüística de Cartagena durante la Edad Media», Historia de Cartagena, Murcia, vol. VI, págs. 407-420.

Grandal López, A. (1996-1997): «Algunes empremtes de la permanència del català a la comarca de Cartagena (Múrcia): del segle XIII al XVI», Quaderns de Migjorn, ${ }^{\circ}$ 3, Alicante, págs. 103-116.

Lapesa, R. (1968): Historia de la lengua española, Madrid.

Muñoz Garrigós, J. (1993): «Cartagena, Habla de», Gran Enciclopedia de la Región de Murcia, Murcia, vol. III, pág. 99.

Rohlfs, G. (1970): Grammatica storica della lingua italiana e dei suoi dialetti: fonetica, Turín.

Torres Sánchez, R. (1994): «Evolución de la población de Cartagena durante la época de los Austrias (siglos XVI-XVII)», Historia de Cartagena, Murcia, vol. VII, págs. $29-94$.

Torres Sánchez, R. (1998): Ciudad y población: el desarrollo demográfico de Cartagena durante la Edad Moderna, Cartagena.

Zamora Vicente, A. (1974): Dialectología española, Madrid.

\section{Ilustraciones}

1.- Caja 79 , Expediente $28, \mathrm{f}^{\mathrm{o}} 19 \mathrm{r}^{\mathrm{o}}$ (1505). Véase: Sanches ( $2^{\mathrm{a}}$ y $13^{\mathrm{a}}$ línea), Rodriguez $\left(3^{\mathrm{a}}\right)$, cafis $\left(6^{\mathrm{a}}\right)$, cahiz $\left(8^{\mathrm{a}}\right)$, Minguez $\left(11^{\mathrm{a}}\right)$, Gonçales $\left(16^{\mathrm{a}}\right)$, tresientos $\left(20^{\mathrm{a}}\right.$ y $\left.21^{\mathrm{a}}\right)$.

2.- Caja 112, Expediente $29, \mathrm{f}^{\mathrm{o}} 2 \mathrm{r}^{\mathrm{o}}(1560)$. Véase: veses ( $4^{\mathrm{a}}$ línea), conçervar $\left(6^{\mathrm{a}}\right)$, nessesidad $\left(7^{\mathrm{a}}\right)$, haser $\left(9^{\mathrm{a}}\right)$, poçito (corregido, $\left.9^{\mathrm{a}}\right)$, proviçion $\left(11^{\mathrm{a}}\right)$, depoçito $\left(12^{\mathrm{a}}\right)$, haser $\left(22^{\mathrm{a}}\right)$. 


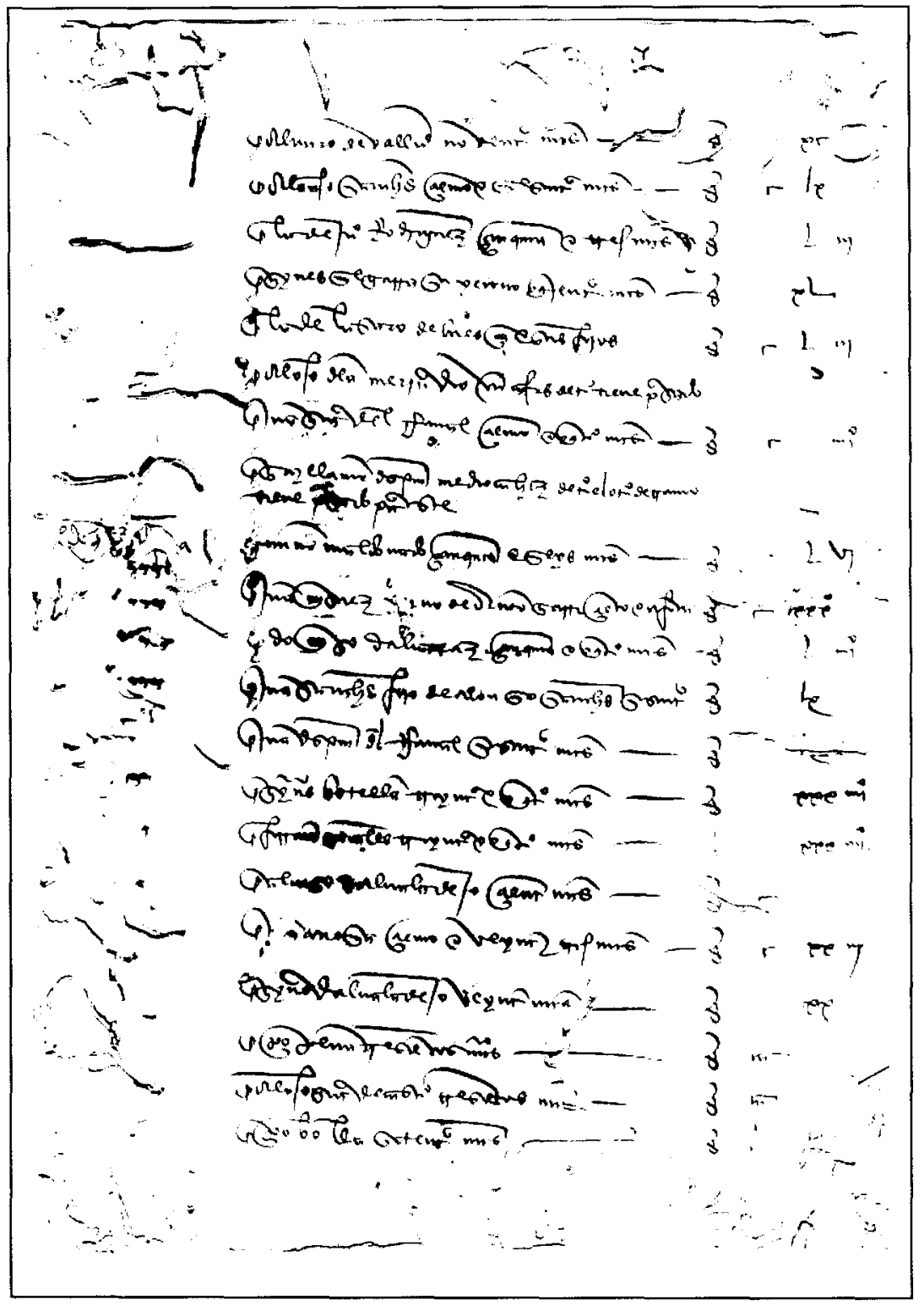




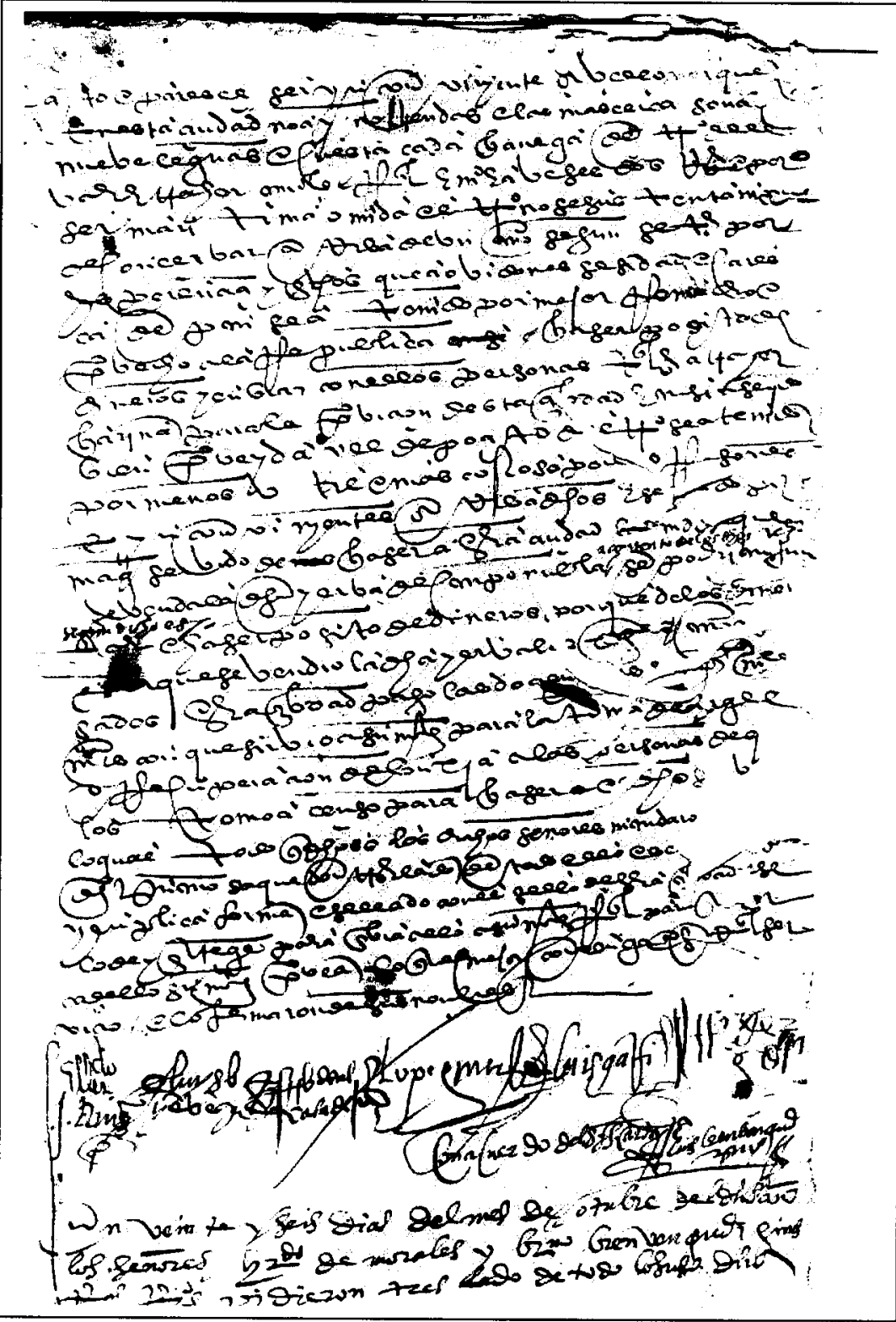

